\title{
In vivo evaluation of hot water extract of Acorus gramineus root against benign prostatic hyperplasia
}

\author{
Joo-Myung Moon ${ }^{1 \dagger}$, Hae-Mi Sung ${ }^{2 \dagger}$, Hyun-Jung Jung ${ }^{2}$, Jae-Won Seo ${ }^{1}$ and Ji-Hyang Wee ${ }^{2^{*}}$
}

\begin{abstract}
Background: Acorus gramineus has been reported to exhibit various pharmacological effects including inhibition of cholesterol synthesis, enhancement of lipid metabolism, prevention of dementia and inhibition of mast cell growth. According to the Chinese compendium of materia media, it has been reported that Acorus spp. is effective for sedation, dementia prevention as well as diuretic effect. In addition, it showed more than equivalent activity compared to furosoemide, a drug known to be effective in diuretic action in animal model study. However, their effectiveness against benign prostatic hyperplasia (BPH) of Acorus gramineus has not been reported. This study was designed to evaluate the effect of Acorus gramineus root hot water extract (AG) against BPH in vivo.
\end{abstract}

Methods: Male rats, 10 weeks of age and weighing $405 \mathrm{~g} \pm 10 \mathrm{~g}$, were used for this study. Biomarkers were evaluated including prostate weight, prostate weight ratio, hormonal changes, 5-a reductase type II androgen receptor (AR) of the prostate gland and anti-oxidant activation factors related to $\mathrm{BPH}$. These biomarkers were measured in vivo test.

Results: AG showed significant effect at the 250 and $500 \mathrm{mg} / \mathrm{kg} /$ day in rats. Groups treated with AG displayed significantly lower levels of prostate gland weight $(0.79 \mathrm{~g})$ compared to the BPH induced group (1.19 g). Also, dihydrotestosterone (DHT) level was decreased from 61.8 to $100 \%$ and androgen receptor expression level was decreased from 111 to 658\%. Any hematological toxicity of alanine aminotransferase (ALT) and aspartate aminotransferase (AST) level wasn't observed.

Conclusion: This study indicated that AG was effective for reducing BPH symptoms.

Trial registration: Not applicable.

Keywords: Acorus gramineus, Benign prostatic hyperplasia, 5-a reductase, Anti-oxidant activation androgen receptor

\section{Background}

At andropause, the level of the male hormones such as testosterone decrease. In contrast, level of the female hormones like estrogen increase. Various symptoms occur including decreased bone density, muscle mass, concentration and sexual desire. Additionally, depression, headache, insomnia, fatigue, an increase in abdominal fat and a decrease in general physical strength occur [1-3].

* Correspondence: happyweedy@nate.com

${ }^{\dagger}$ Equal contributors

${ }^{2}$ Food Research Center, Jeonnam Bio-industry Foundation, 30-5

Dongsunonggongdanji-gil, Naju-si, Jeollanam-do 58275, Republic of Korea

Full list of author information is available at the end of the article
Male hormone deficiency symptoms are called the Andropause syndrome which is described by six characteristic complex symptoms such as the decrease of sexual vigor, emotional changes, the increase of body fat, the decrease of body hair, osteoporosis and abdominal obesity [1-3].

Males enter andropause in their forties and experience the above mentioned symptoms in addition to benign prostatic hyperplasia, the gradational enlargement of the prostate gland [4]. An enlarged prostate gland suppresses the urethra where it enters the prostate and urine excretion is interrupted, causing inflammation. 
$\mathrm{BPH}$ occurs more frequently than hypertension and diabetes. In fact, $40 \%$ of men in their forties, $50 \%$ of men in their fifties, $60 \%$ of men in their sixties and $70 \%$ of men in their seventies experience histological BPH. Of these, 25\% experience clinical symptoms of BPH [5]. Pharmaceutical treatments of BPH have been classified as follows: $\alpha-1$ inhibitors as improve urination; $5-\alpha$ reductase inhibitors that reduce the prostate size. The representative drug, finasteride is 5 - $\alpha$ reductase inhibitor used for $\mathrm{BPH}$ but it is associated with a variety of side effects [6].

Acorus gramineus is perennial plant that has green leaves during all four seasons. It is found in Korea, China, Japan and India [7]. The root and stem contain $0.5 \sim 0.8 \%$ essential oil and its main components are $\gamma$ aminobutyric acid (GABA), asarone, palmitic acid, phenol, calamenol, palmitin $[8,9]$.

Asarone has various pharmacological effects. $\alpha$-asarone is effective for inhibiting cholesterol synthesis and enhancing lipid metabolism [10]. $\beta$-asarone is effective for preventing dementia and is used as a pharmaceutical ingredient. $\beta$ asarone was reported to inhibit cell growth and cause cell contraction when injected into mast $[11,12]$. Some countries have registered Acorus gramineus as a toxic material because of $\beta$-asasone. However, Korean Food Standard Codex permits the water extract for use in food [13]. We removed most of the $\beta$-asasone in Acorus gramineus by hot water extraction.

This study was designed to evaluate the effectiveness of Acorus gramineus root hot water extract (AG) for the treatment of $\mathrm{BPH}$ in vivo.

\section{Methods}

\section{Material preparation and analytic method Instruments}

Extraction concentrator was purchased from Seugyung Eng. (Ansan, Korea). Agilent Infinity 1260 was used for qualitative and quantitative analysis of Acorus gramineus extract.

\section{Materials and reagents}

Methanol and acetonitrile were purchased from J.T. \& Baker (Pennsylvania, USA). Hydrochloride was purchased from JUNSEI (Tokyo, Japan). Phosphoric acid and sodium phosphate dibasic anhydrous $\left(\mathrm{Na}_{2} \mathrm{HPO}_{4}\right)$ were purchased from SAMCHUN (Sung-nam, Korea). Borate buffer (3-mercaptopropionic acid in borate buffer) and OPA (Ortho-Phthal aldehyde) was purchased from Agilent (Santa Clara, (California), USA). GABA standard material was purchased from SigmaAldrich (St. Louis, (Missouri), USA). Finasteride was purchased from Tokyo Chemical Industry Co. Ltd. (Tokyo, Japan).

\section{AG extraction method}

Acorus gramineus root was purchased from Umji, cultivated at Jeju Island in Korea and harvested in September 2014. Acorus gramineus was confirmed by BTC R\&D center in accordance with the confirmation test method of The Korean Herbal Pharmacopoeia. A voucher specimen was deposited at the Herbarium of the ChonBuk National University, Republic Of Korea. AG was produced as follows: $1 \mathrm{~kg}$ of dried Acorus gramineus root and $20 \mathrm{~kg}$ of water were placed into the extraction concentrator and extracted for $6 \mathrm{~h}$ at $90{ }^{\circ} \mathrm{C}$. Then extract was filtered by 200 mesh net. The filterate was then concentrated using an evaporator at $65{ }^{\circ} \mathrm{C}$ and dried using a vacuum dryer (Ilshin Corp., Korea). A total of $215 \mathrm{~g}$ of extract powder was obtained. Based on the HPLC analysis, GABA was selected as the indicator material in Acorus gramineus

\section{Analytic method \\ Sample solution preparation}

GABA consists of single bond so it cannot absorb UV/ Vis light. Because of this, it is necessary to derivatize a compound that has absorption ability and $\mathrm{HCl}$ was used for derivatization. Distilled water $1 \mathrm{~L}$ included $8.8 \mathrm{~mL}$ of $35 \% \mathrm{HCl}$ were combined in $1 \mathrm{~L}$ volumetric flask and $1.2 \mathrm{~g}$ of AG was mixed for $10 \mathrm{~min}$.

\section{Standard solution preparation}

GABA standard $250 \mathrm{mg}$ was added to a $250 \mathrm{~mL}$ flask and dissolved by solution that made to sample solution. Then, the mixture was shaken for $5 \mathrm{~min}$ with an ultrasonic shaker. The resulting solution was diluted to the standard solution concentrations: 50, 80, 100, 150, $200 \mu \mathrm{g} / \mathrm{mL}$.

\section{Derivatization and HPLC-DAD analyzing conditions}

The hydrolyzed sample was automatically derivatized with OPA (Ortho-Phthal aldehyde) in accordance with the agilent autosampler program. An amount of $36.5 \mu \mathrm{L}$ sample was injected on a Zorbax Eclipse AAA column, $4.6 \times 150 \mathrm{~mm}$, particle size $3.5 \mu \mathrm{m}$ (Agilent, USA), at $40{ }^{\circ} \mathrm{C}$. The mobile phase (A) $40 \mathrm{mM} \mathrm{Na}_{2} \mathrm{HPO}_{4}$ in $0.1 \%$ $\mathrm{H}_{3} \mathrm{PO}_{4}$ in distilled water and (B) acetonitrile was applied as follows: $0.0-0.9 \mathrm{~min}, 15 \% \mathrm{~B}$; $1.9-10.0 \mathrm{~min}, 15-57 \% \mathrm{~B}$; $10.0-10.5 \mathrm{~min}, 57-80 \% \mathrm{~B}$; $10.5-13.0 \mathrm{~min}, 80 \% \mathrm{~B}$ and reequilibration of the column over $15 \mathrm{~min}$. The flow rate

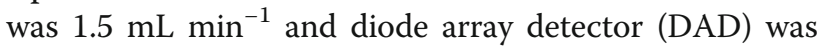
used for acquiring chromatograms at $338 \mathrm{~nm}$.

\section{Experimental animal treatment}

Experimental rats (age 10 weeks, weight $405 \pm 10$ g) were purchased from Orient-Bio Ltd. (Sung-nam, Korea). Animals were housed at $22 \pm 2{ }^{\circ} \mathrm{C}$, with $55 \pm 5 \%$ humidity and a $12 \mathrm{~h}$ dark/light cycle. They were provided access to 
food and water ad libitum. The institutional Animal Care and Use Committee National University (Kwangju, Korea) approved the protocol for the animal study and the animals were cared for in accordance with the "Guidelines for Animal Experiment" established by the university.

\section{$\mathrm{BPH}$ induction and treatment}

Rats were randomly divided into a control group $(n=7)$ and a $\mathrm{BPH}$ induced group $(n=35)$. To induce $\mathrm{BPH}$, $3 \mathrm{mg} / \mathrm{kg}$ of testosterone propionate (TP) was injected daily for 4 weeks [14].

The $\mathrm{BPH}$ induced group was further divided into a control group, an AG medicated group and finasteridetreated group. These groups were fed AG (100, 250, or $500 \mathrm{mg} / \mathrm{kg}$ daily) and finasteride $(10 \mathrm{mg} / \mathrm{kg}$ daily $)$ respectively by oral ingestion over 4 weeks.

\section{Castration}

After maintained 1 week, animals were castrated to remove any internal testosterone influence. The rats were anesthetized with $\mathrm{CO}_{2}$ and ether, both sides of the scrotum were incised to expose the testicles and the epididymis and the spermatic cord, vascular tracts and incised part were sutured.

Castration was executed referring to the OECD Hershberger assay method provided by the Institute of National Toxicity Laboratory. One week after castration, the rats were used for experiments [15].

\section{Measurement of body weight and feeding efficiency}

Initial body weight was recorded 1 week after castration. During the 8 weeks experimental period, body weight was measured every 3 days and the TP injection quantity and feeding quantity were recorded.

Prior to dissection, the rats were fasted for $12 \mathrm{~h}$ and a final body weight was recorded. Body weight variation in the experimental animals was described as weight gain. Feeding efficiency was calculated using the food efficiency ratio (FER) based on the feeding quantity of the experimental animals [16].

\section{Organ weight and storage}

Rats were anesthetized with $\mathrm{CO}_{2}$ and the abdomen was cut open to expose the organs. The organs were weighed then stored at $-80^{\circ} \mathrm{C}$ after being washed once with $1 \times$ PBS solution [17].

\section{Analysis of plasma alanine aminotransferase (ALT) and aspartate aminotransferase (AST)}

Experimental animal serum was separated from blood after centrifugation at $890 \times g$. ALT and AST were measured at $505 \mathrm{~nm}$ wave length using spectrophotometer (MQS200R; BioTek Instruments, Inc., Winooski, VT, USA).
The results were converted to Karmen units and compared to each other [18].

\section{Measurement of testosterone and DHT in blood}

Testosterone content was measured with an assay kit (Enzo Life Sciences, Farmingdale, NY, USA) using the following method. Serum $(100 \mu \mathrm{L})$ was mixed with testosterone enzyme immunoassay (EIA) antibody $(50 \mu \mathrm{L})$ and cultured for $1 \mathrm{~h}$. Thereafter, $50 \mu \mathrm{L}$ of conjugate was added and the solution was cultured for $1 \mathrm{~h}$. After washing with washing solution, $200 \mu \mathrm{L}$ of $\mathrm{pNpp}$ substrate solution was added and allowed to for 1 h. $50 \mu \mathrm{L}$ of stop solution, solution of trisodium phosphate in water, was then added to stop the reaction and the absorbance was measured at $405 \mathrm{~nm}$ wave length. Testosterone content was calculated using a testosterone standard curve.

DHT content was measured using an assay kit (Biovendor, Brno, Czech Republic). Serum (50 $\mu \mathrm{L})$ was mixed with conjugate $(100 \mu \mathrm{L})$ and left for $1 \mathrm{~h}$ at $25^{\circ} \mathrm{C}$. The mixture was washed three times with washing buffer, then $150 \mu \mathrm{L}$ of 3,3,5,5'-Tetramethylbenzidine (TMB) substrate was added and the mixture was allowed to react for $15 \mathrm{~min}$. Thereafter, $50 \mu \mathrm{L}$ of stop solution was added to stop the reaction and the absorbance was measured at $405 \mathrm{~nm}$ wavelength. DHT content was calculated using a DHT standard curve [19].

\section{Measurement of gene expression rate in the prostate}

Gene expression in the prostatic gland was measured using a real-time polymerase chain reaction (RT-PCR) method. After washing the exposed organ with $1 \times$ PBS, $0.5 \mathrm{~mL}$ of TRIzol reagent (Life technologies, Carlsbad, CA) was used to extract the RNA. cDNA was synthesized as follows: $1 \mu \mathrm{g}$ of extracted RNA, $2 \mu \mathrm{L}$ of gDNA buffer, $1 \mu \mathrm{L}$ of reverse transcriptase, $4 \mu \mathrm{L}$ of $\mathrm{RT}$ buffer and $1 \mu \mathrm{L}$ of RT primer was mixed and allowed to react at $42{ }^{\circ} \mathrm{C}$ for $50 \mathrm{~min}$, then at $70{ }^{\circ} \mathrm{C}$ for $15 \mathrm{~min}$.

Relative mRNA levels of prostate genes, including 5- $\alpha$ reductase type I, 5- $\alpha$ reductase type II, AR and the inflammatory genes, IL-1 $\beta$ (Interleukin- $1 \beta$ ), IL-6, COX-2 (Cyclooxygenase-2) and iNOS (inducible nitric oxide synthase), were measured using RT-PCR with a RotorGene SYBR Green PCR kit (Qiagen, Hilden, Germany). Finasteride was used as a positive control [20]. Quantitative PCR amplification was performed in triplicate using the QuantiTect Promer assay (QT00070518 for SRD5A2, QT00073451 for AR and QT01680476 for ACTB; Qiagen).

IL-1 $\beta$, IL-6, COX-2 and iNOS PCR primers were as follows: IL- $1 \beta$, Forward primer: 5 '-TTCGACACATGGG ATAACGA-3', Reverse primer: 5' -TCTTTCAACACGC AGGACAG-3'; IL-6, Forward primer: 5'-TACCCCC AGGAGAAGATTCC-3', Reverse primer: 5' -TTTTCTG CCAGTGCCTCTTT-3'; COX-2, Forward primer: $5^{\prime}-\mathrm{T}$ 
Table 1 Initial and final body weight, change of body weight and feeding efficiency

\begin{tabular}{lllllll}
\hline Group & No. of Rats & Initial BW (g) & Final BW (g) & BW Gain (g) & FER (\%) & Survival Rate (\%) \\
\hline Control & 7 & $404.6 \pm 2.4^{\mathrm{a}}$ & $534.4 \pm 12.3^{\mathrm{b}}$ & $111.8 \pm 10.2^{\mathrm{b}}$ & $1.00 \pm 0.09^{\mathrm{b}}$ & 100 \\
BPH & 7 & $406.5 \pm 9.2^{\mathrm{a}}$ & $470.6 \pm 18.4^{\mathrm{a}}$ & $64.1 \pm 11.6^{\mathrm{a}}$ & $0.41 \pm 0.07^{\mathrm{a}}$ & 100 \\
BPH + AG 100 mg & 7 & $405.0 \pm 8.2^{\mathrm{a}}$ & $451.6 \pm 11.3^{\mathrm{a}}$ & $46.6 \pm 7.2^{\mathrm{a}}$ & $0.30 \pm 0.04^{\mathrm{a}}$ & 100 \\
BPH + AG 250 mg & 7 & $406.2 \pm 8.8^{\mathrm{a}}$ & $459.0 \pm 11.0^{\mathrm{a}}$ & $52.9 \pm 4.5^{\mathrm{a}}$ & $0.35 \pm 0.03^{\mathrm{a}}$ & 100 \\
BPH + AG 500 mg & 7 & $403.5 \pm 4.3^{\mathrm{a}}$ & $444.9 \pm 5.1^{\mathrm{a}}$ & $41.4 \pm 5.3^{\mathrm{a}}$ & $0.26 \pm 0.03^{\mathrm{a}}$ & 100 \\
Finasteride & 7 & $405.1 \pm 9.3^{\mathrm{a}}$ & $455.5 \pm 17.4^{\mathrm{a}}$ & $50.5 \pm 12.5^{\mathrm{a}}$ & $0.33 \pm 0.05^{\mathrm{a}}$ & 100 \\
\hline
\end{tabular}

Data express the mean \pm S.E. The letters in the columns indicate statistical differences by Duncan's multiple range test ( $p<0.05)$. Control: Normal rat supplied with tap water, BPH: Castrated rat supplied with tap water, AG 100: Castrated rat supplied with AG $100 \mathrm{mg} / \mathrm{kg}$ of BW daily, AG 250: Castrated rat supplied with AG $250 \mathrm{mg} / \mathrm{kg}$ of BW daily, AG 500: Castrated rat supplied with AG $500 \mathrm{mg} / \mathrm{kg}$ of BW daily. Data are represented as mean $\pm S E M$. a, $\mathrm{P}<0.05$ vs. control, $\mathrm{b}, \mathrm{P}<0.01 \mathrm{vs}$. control, $\mathrm{C}, \mathrm{P}<0.001$ vs. control

GCTGTGGAGCTGTATCCTG-3', Reverse primer: 5'-C GGGAAGAACTTGCATTGAT-3' and iNOS, Forward primer: 5'-CTCACTGGGACTGCACAGAA-3', Reverse primer: 5'-GCTTGTCTCTGGGTCCTCTG-3'.

\section{Measurement of protein expression rate in the prostate}

Protein expression rate in the prostate gland was measured by sodium dodecyl sulfate-polyacrylamide gel electrophoresis (SDS-PAGE). After washing the exposed prostate gland with $1 \times$ PBS (Phosphate buffered saline), $\mathrm{KCl}$ lysis buffer was added, allowed to react at $4{ }^{\circ} \mathrm{C}$ for $1 \mathrm{~h}$ and centrifuged at $16600 \times \mathrm{g}$ for $20 \mathrm{~min}$ at $4{ }^{\circ} \mathrm{C}$. The supernatant was collected and the protein concentration was measured using a BCA (Bicinchoninate) protein quantification method (Amersham, Waltham, MA, USA).

Thirty micrograms of total protein extract was loaded on $4-10 \%$ polyacrylamide gel (Life Technologies, Seoul, Korea) for SDS-PAGE. Separated proteins were transferred to PVDF (Polyvinylidene difluoride) membranes (Life Technologies). Blocking was performed using TBS$\mathrm{T}$ (Tris-buffered saline) buffer $(0.1 \%$ Tween $20,5 \%$ bovine serum albumin) on a shaker for $1 \mathrm{~h}$ at $4{ }^{\circ} \mathrm{C}$, then the membrane was washed with TBS-T buffer. COX-2, phosphorylated NF- $\kappa B$ (Nuclear factor kappa B), NF- $k B$, 5 - $\alpha$ reductase type II and $\beta$-actin antibody (Cell Signaling Technology, Beverly, MA, USA) were diluted 1:1000 and attached for $16 \mathrm{~h}$ at $4{ }^{\circ} \mathrm{C}$. After washing the membrane,
anti-Rabbit IgG secondary antibody (Cell Signaling Technology) was attached and the membrane was rewashed. Finally, Amersham ECL (Enhanced chemiluminescence) prime western blotting detection reagent was used to treat the membrane and results were analyzed using an image reader (Supernova 1800, Lugen Sci So., LTD. Bucheon, Korea) [21].

\section{Hematoxylin \& eosin (H\&E) staining}

The prostate glands were sliced to an approximately $10 \mu \mathrm{m}$ thickness, attached to slides and left for $5 \mathrm{~min}$. The slides were then washed with flowing water for 5 min, prepared with 94\% ethyl alcohol for $1 \mathrm{~min}$ and washed with flowing water for $30 \mathrm{~s}$. The slices were stained with hematoxylin for $1 \mathrm{~min}$, washed in flowing water for $30 \mathrm{~s}$, then stained with eosin for $30 \mathrm{~s}$. The slices were again washed with $94 \%$ ethyl alcohol two times for $30 \mathrm{~s}$, treated with absolute alcohol for $30 \mathrm{~s}$, washed with xylene for $30 \mathrm{~s}$ and washed with flowing water for $30 \mathrm{~s}$ [15].

\section{Statistical analysis}

Results are expressed as mean \pm standard error of the mean (SEM). Data were analyzed using one-way analysis of variance (ANOVA). Differences in each group were considered significant at $p<0.05$ by Duncan's multiple range test.

Table 2 Organ weight and prostate weight ratio

\begin{tabular}{|c|c|c|c|c|c|}
\hline Group & Liver (g) & Kidney (g) & Spleen (g) & Prostate (g) & Prostate ratio $(\mathrm{mg} / 100 \mathrm{~g}$ of $\mathrm{BW})$ \\
\hline Control & $11.48 \pm 0.44^{a}$ & $3.81 \pm 0.06^{\mathrm{a}}$ & $0.65 \pm 0.02^{a}$ & $0.59 \pm 0.03^{d}$ & $0.13 \pm 0.01^{d}$ \\
\hline $\mathrm{BPH}$ & $11.39 \pm 0.47^{a}$ & $3.75 \pm 0.15^{a}$ & $0.64 \pm 0.03^{\mathrm{a}}$ & $1.19 \pm 0.11^{\mathrm{a}}$ & $0.26 \pm 0.03^{a}$ \\
\hline $\mathrm{BPH}+\mathrm{AG} 100 \mathrm{mg}$ & $11.66 \pm 0.86^{\mathrm{a}}$ & $3.50 \pm 0.11^{\mathrm{a}}$ & $0.62 \pm 0.02^{\mathrm{a}}$ & $0.99 \pm 0.08^{\mathrm{ab}}$ & $0.22 \pm 0.03^{\mathrm{ab}}$ \\
\hline $\mathrm{BPH}+\mathrm{AG} 250 \mathrm{mg}$ & $12.39 \pm 0.30^{a}$ & $3.70 \pm 0.06^{\mathrm{a}}$ & $0.69 \pm 0.03^{\mathrm{a}}$ & $0.87 \pm 0.09^{b}$ & $0.19 \pm 0.02^{b}$ \\
\hline $\mathrm{BPH}+\mathrm{AG} 500 \mathrm{mg}$ & $11.19 \pm 0.25^{\mathrm{a}}$ & $3.50 \pm 0.06^{\mathrm{a}}$ & $0.69 \pm 0.03^{\mathrm{a}}$ & $0.79 \pm 0.04^{c}$ & $0.18 \pm 0.03^{c}$ \\
\hline Fisnasteride & $11.85 \pm 0.45^{\mathrm{a}}$ & $3.57 \pm 0.07^{\mathrm{a}}$ & $0.70 \pm 0.06^{\mathrm{a}}$ & $0.82 \pm 0.06^{c}$ & $0.18 \pm 0.03^{c}$ \\
\hline
\end{tabular}

Data express the mean \pm S.E. The letters in the columns indicate statistical differences by Duncan's multiple range test $(p<0.05)$. Control: Normal rat supplied with tap water, BPH: Castrated rat supplied with tap water, AG 100: Castrated rat supplied with AG $100 \mathrm{mg} / \mathrm{kg}$ of BW daily, AG 250: Castrated rat supplied with AG $250 \mathrm{mg} / \mathrm{kg}$ of BW daily, AG 500: Castrated rat supplied with AG $500 \mathrm{mg} / \mathrm{kg}$ of BW daily. Data are represented as mean \pm SEM. a, $P<0.05$ vs. control, b, P<0.01 vs. control, $C, P<0.001$ vs. control 
Table 3 Blood toxicity estimation in the blood

\begin{tabular}{lllcccc}
\hline & Control & BPH & BPH + AG 100 mg & BPH + AG 250 mg & BPH + AG 500 mg & Finasteride \\
\hline AST & $166.8 \pm 6.1^{\mathrm{a}}$ & $171.6 \pm 5.4^{\mathrm{a}}$ & $171.5 \pm 10.4^{\mathrm{a}}$ & $175.5 \pm 3.5^{\mathrm{a}}$ & $167.1 \pm 16.1^{\mathrm{a}}$ & $169.5 \pm 9.5^{\mathrm{a}}$ \\
Karmen $/ \mathrm{mL}$ & & & & $141.9 \pm 3.8^{\mathrm{a}}$ & $138.8 \pm 6.6^{\mathrm{a}}$ & $146.3 \pm 7.1^{\mathrm{a}}$ \\
ALT & $133.1 \pm 5.2^{\mathrm{a}}$ & $143.9 \pm 8.4^{\mathrm{a}}$ & $146.6 \pm 4.6^{\mathrm{a}}$ & & \\
Karmen $/ \mathrm{mL}$ & & & & &
\end{tabular}

Data express the mean \pm S.E. The letters in the columns indicate statistical differences by Duncan's multiple range test $(p<0.05)$. Control: Normal rat supplied with tap water, BPH: Castrated rat supplied with tap water, AG 100: Castrated rat supplied with AG 100 mg/kg of BW daily, AG 250: Castrated rat supplied with AG $250 \mathrm{mg} / \mathrm{kg}$ of BW daily, AG 500: Castrated rat supplied with AG $500 \mathrm{mg} / \mathrm{kg}$ of BW daily. Data are represented as mean $\pm S E M$. $a, P<0.05$ vs. control, $b, P<0.01 \mathrm{vs}$. control, $\mathrm{c}, \mathrm{P}<0.001$ vs. control

\section{Results}

\section{Change in body weight and organ weight} Body weight and feeding efficiency

In case of $\mathrm{BPH}$ induced group, it was reduced to a significant reduction in weight about $47.7 \mathrm{~g}$ compared to control group. After the end of the experiment, measured weight was $451.6 \pm 11.3,459.0 \pm 11.0$, $444.9 \pm 5.1$ and $455.5 \pm 17.4 \mathrm{~g}$ in the AG 100, 250 and $500 \mathrm{mg} / \mathrm{kg} /$ day and finasteride treated groups, respectively. Table 1 shows body weight and feeding efficiency ratio.

\section{Organ weight and weight ratio of the prostate gland}

The weights of the liver, kidney and spleen were not significantly different among the control, $\mathrm{BPH}$, finasteridetreated and AG-treated groups.

Prostate gland weight and weight ratio in the $\mathrm{BPH}$ induced group were significantly higher than those of the control group. However, prostate gland weight and weight ratio in the 250 and $500 \mathrm{mg} / \mathrm{kg} /$ day of AG and finasteride-treated group were significantly lower than those of the BPH induced group (Table 2).

\section{Toxicity and BPH hormones in blood Toxicity estimation in the blood (ALT, AST)}

ALT and AST values were not significantly different among the $\mathrm{BPH}$, finasteride and AG-treated groups. Therefore, the results indicated that our samples were not toxic. Table 3 shows results of the toxicity evaluation.

\section{$B P H$ related hormones (testosterone and DHT) in the blood} AG and finasteride treated groups showed a significantly lower testosterone and DHT concentration compared to the $\mathrm{BPH}$ induced group (Fig. 1).

\section{BPH-related gene expression}

5 - $\alpha$ reductase type I gene expression of AG and finasteride treated groups was significantly lower than the $\mathrm{BPH}$ induced group (Fig. 2a). Also, 5- $\alpha$ reductase type II gene expression of AG and finasteride treated groups was significantly reduced compared to $\mathrm{BPH}$ induced group (Fig. 2b).

In the AG-treated groups, the AR gene expression was decreased in a concentration-dependent manner. AR
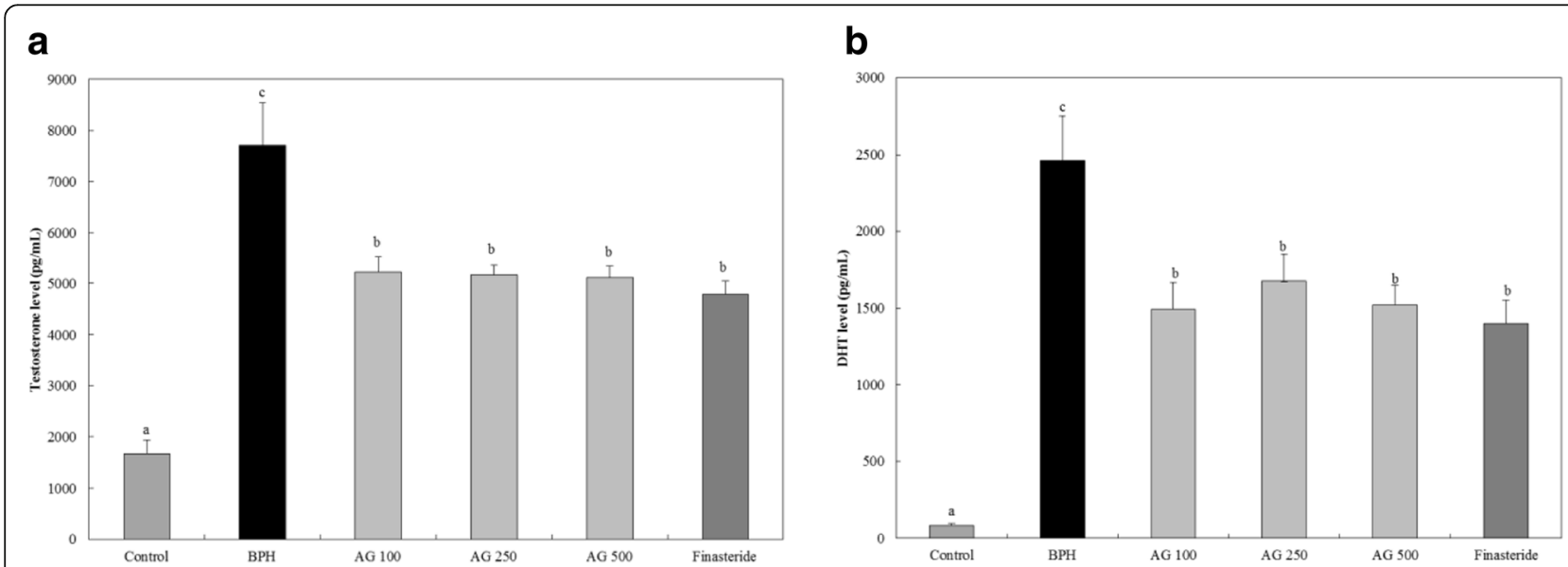

Fig. 1 Effects of AG on DHT and testosterone levels in serum (a) Testosterone level (b) DHT level. Control: water, BPH: 3 mg.kg testosterone propionate, AG 100, AG 250, AG 500: 3 mg/kg testosterone propionate + AG 100 mg/kg, AG 250 mg/kg, AG 500 mg/ $/ \mathrm{kg}$, respectively, Finasteride: $3 \mathrm{mg} / \mathrm{kg}$ testosterone propionate + finasteride $10 \mathrm{mg} / \mathrm{kg}$. Data represented as mean $\pm \mathrm{SD}(n=7)$. Significant difference at $p<0.05 \mathrm{compared}$ with the Control group and $\mathrm{BPH}$ induced group, respectively 
a

5- $\alpha$ reductase type I

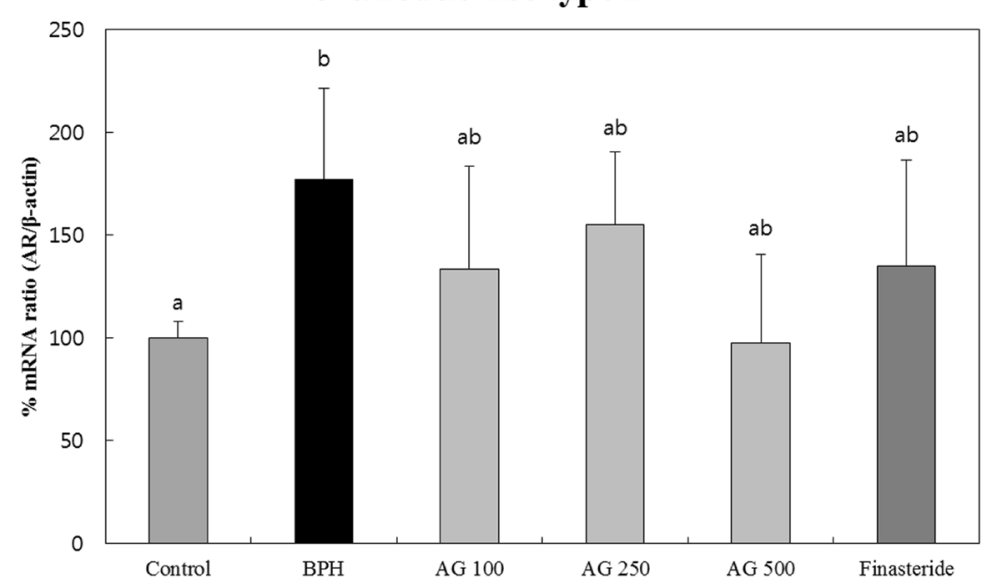

b

5- $\alpha$ reductase type II

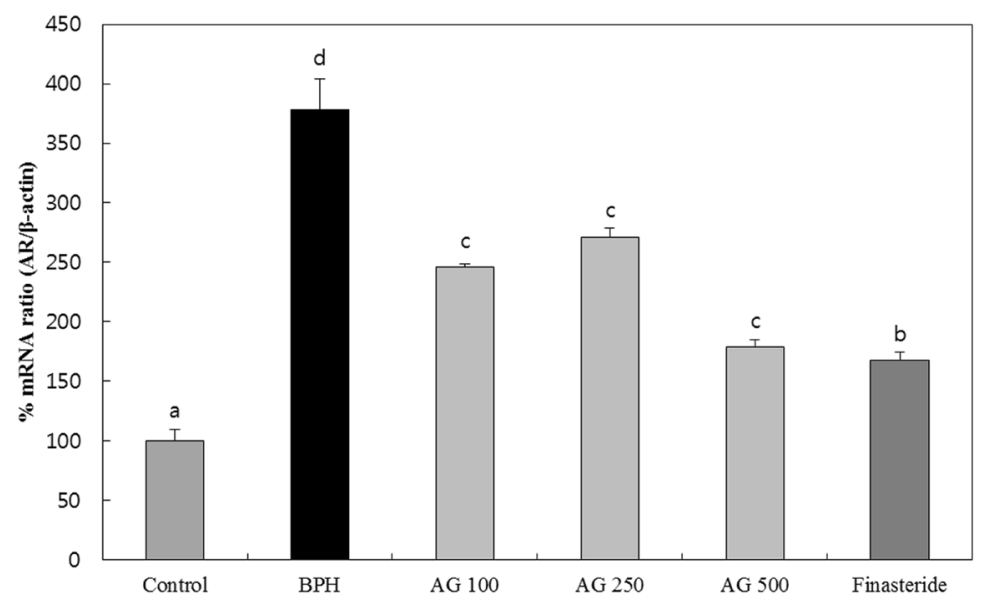

C

Androgen receptor

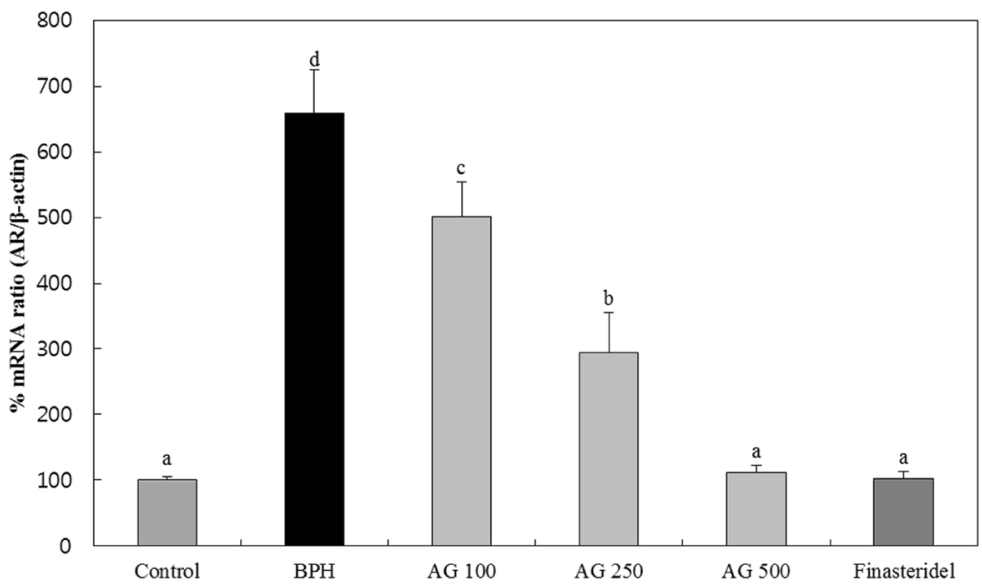

Fig. 2 Effects of AG on expression of BPH-related gene's mRNA in the prostate (a) 5-a reductase type I (b) 5-a reductase type II (c) Androgen receptor. Control: water, BPH: 3 mg/kg testosterone propionate, AG 100, AG 250, AG 500: 3 mg/kg testosterone propionate + AG 100 mg/kg, AG 250 mg/kg, AG $500 \mathrm{mg} / \mathrm{kg}$, respectively, Finasteride: $3 \mathrm{mg} . \mathrm{kg}$ testosterone propionate + finasteride $10 \mathrm{mg} / \mathrm{kg}$. Data represented as mean \pm SD $(n=7)$. Significant difference at $p<0.05$ compared with the Control group and $\mathrm{BPH}$ induced group, respectively 
gene expression of AG $500 \mathrm{mg} / \mathrm{kg} /$ day treated group is as effective as finasteride treatment (Fig. 2c).

\section{Inflammation-related gene expression}

The iNOS gene expression level of AG $500 \mathrm{mg} / \mathrm{kg} /$ day treated group was lower than control group. Also, the expression was decreased in a concentration-dependent manner (Fig. 3a).

Likewise, the gene expression of IL-1 $\beta$, COX-2 and IL-6 of AG $500 \mathrm{mg} / \mathrm{kg} /$ day treated group was lower than control group and decreased in a concentration-dependent manner (Fig. 3b-d). Finasteride treated group showed similar expression level of inflammation-related gene compared to control group.

\section{Western blot analysis of the prostate} $B P H$-related protein expression rate

The protein expression level of $5-\alpha$ reductase II in the control group was significantly decreased from that of the BPH induced group. All of the AG-treated groups had a significantly decreased expression level that was dependent on the dose. Compared to finasteride treated group, the AG 250 and $500 \mathrm{mg} / \mathrm{kg} /$ day treated groups showed more reduced expression level of 5 - $\alpha$ reductase II (Fig. 4a and b).

\section{Inflammation-related protein expression rate}

The BPH induced group had a significantly increased level of COX-2 protein expression and NF- $\mathrm{kB}$ phosphorylation compared to the control group. Otherwise, the level of expression and phosphorylation in AG-treated groups was gradually decreased compared to $\mathrm{BPH}$ induced group. Furthermore, AG $500 \mathrm{mg} / \mathrm{kg} /$ day treated group's level of each protein showed less than finasteride treated group (Fig. 4c and d).

\section{Anti-oxidant indicators in the prostate}

In $\mathrm{BPH}$ induced group, anti-oxidative ability was significantly decreased than control group. However, the ability of AG treated group was increased in a concentration-dependent manner compared to $\mathrm{BPH}$ induced group. AG $500 \mathrm{mg} / \mathrm{kg} /$ day treatment has as effective as finasteride (Table 4).

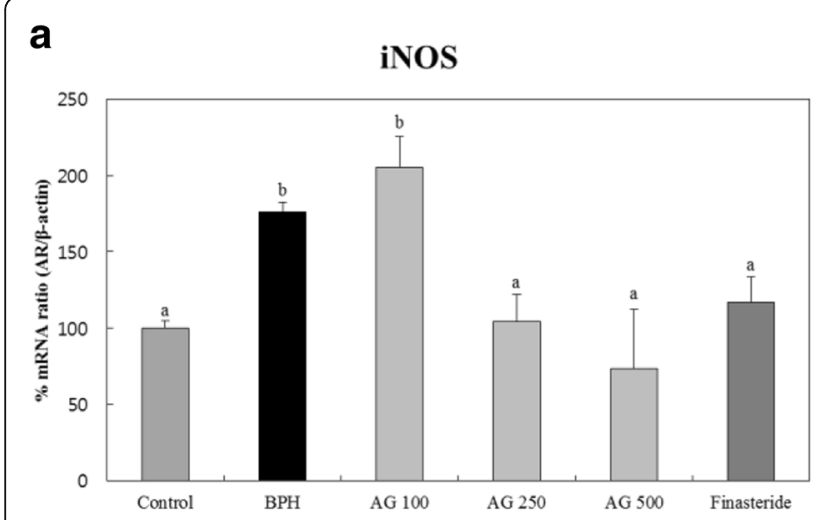

b

b

IL-1;

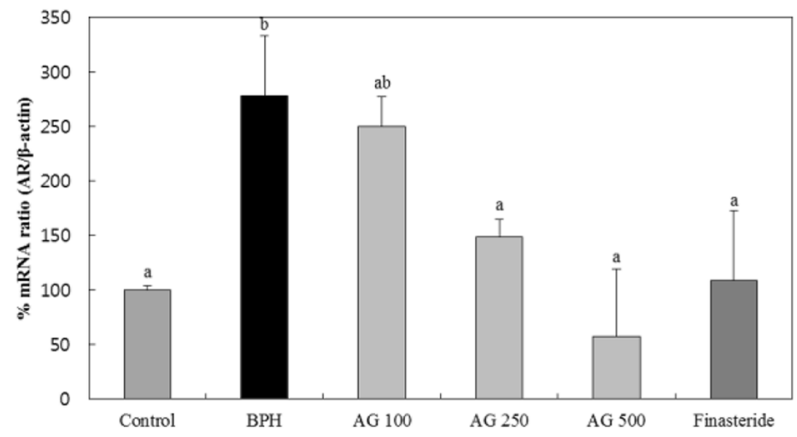

d
IL-6

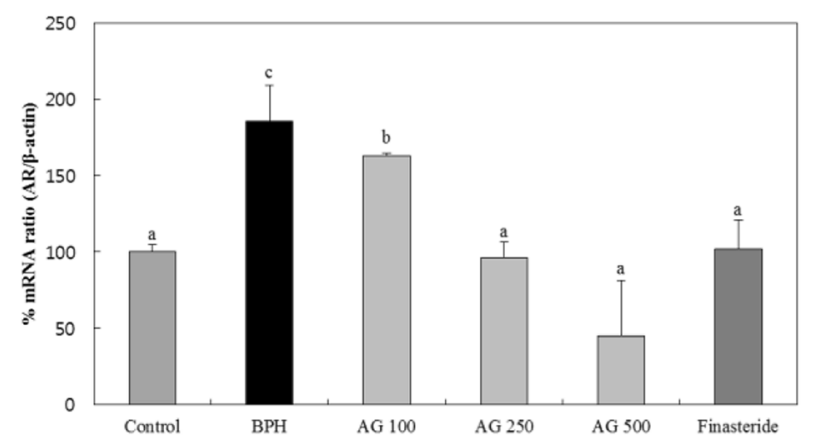

d
C

COX-2

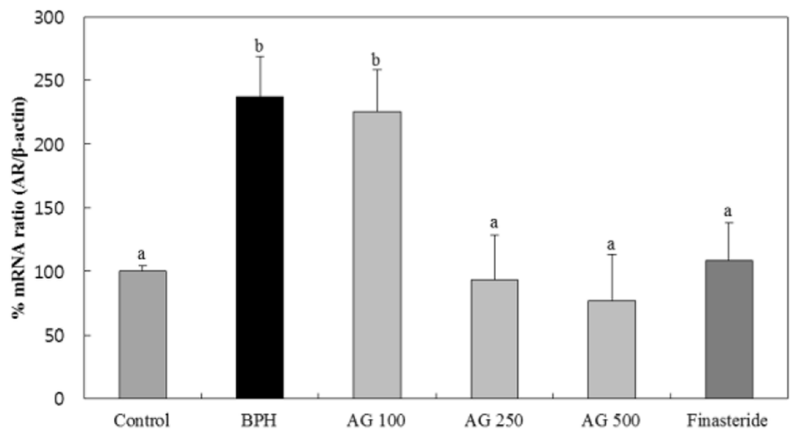

Fig. 3 Effects of AG on expression of Inflammation-related gene's mRNA in the prostate (a) iNOS (b) IL-1 (c) COX-2 (d) IL-6. Control: water, BPH: $3 \mathrm{mg} / \mathrm{kg}$ testosterone propionate, AG 100, AG 250, AG 500: $3 \mathrm{mg} / \mathrm{kg}$ testosterone propionate + AG $100 \mathrm{mg} / \mathrm{kg}$, AG $250 \mathrm{mg} / \mathrm{kg}$, AG 500 mg/kg, respectively, Finasteride: $3 \mathrm{mg} . \mathrm{kg}$ testosterone propionate + finasteride $10 \mathrm{mg} / \mathrm{kg}$. Data represented as mean $\pm \mathrm{SD}(n=7)$. Significant difference at $p<0.05$ compared with the Control group and BPH induced group, respectively 


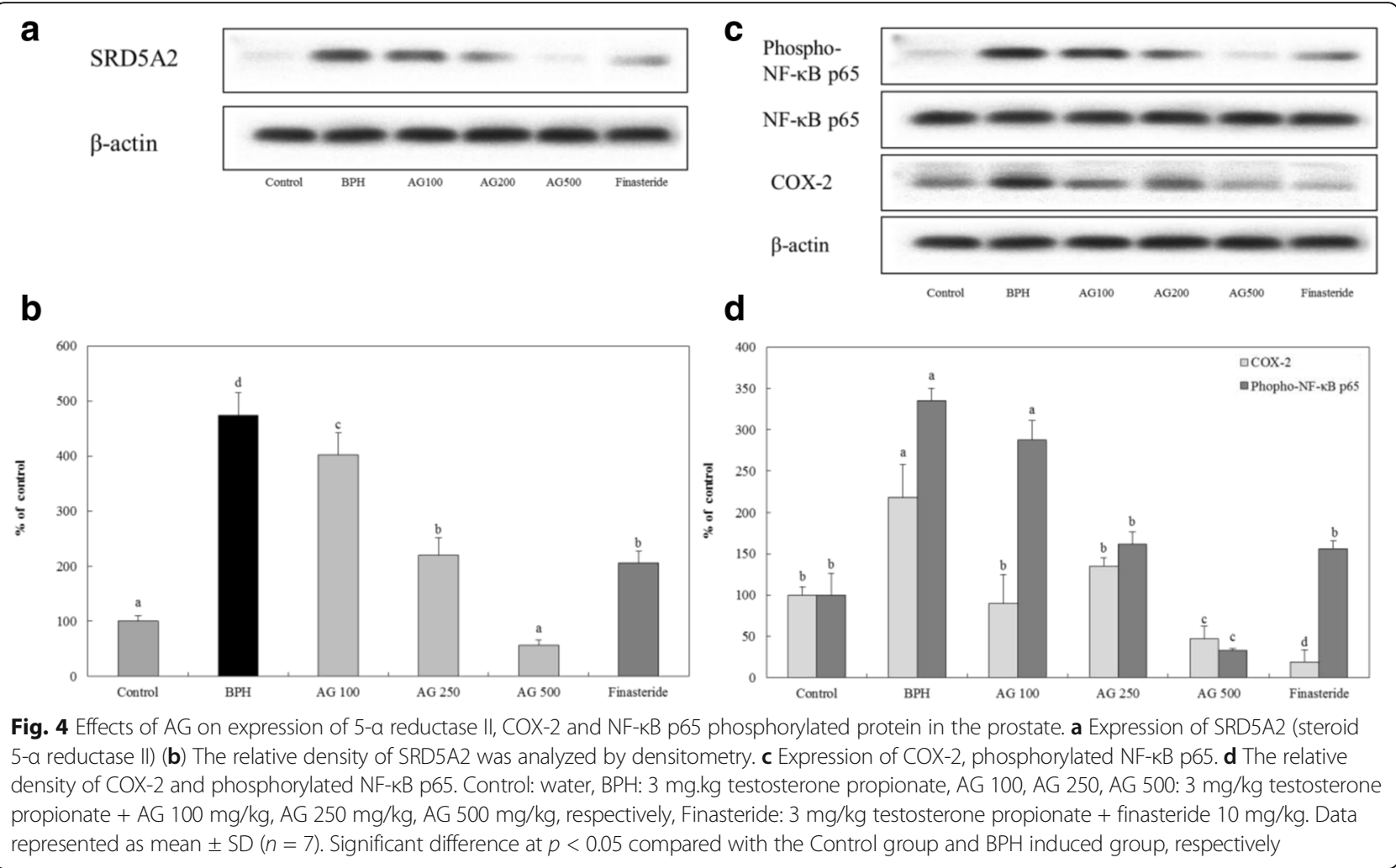

\section{H\&E staining}

To verify the effectiveness of AG in mitigating prostate hypertrophy, H\&E staining was performed and histological variation was observed.

As shown in Fig. 5, the epithelial cells in the prostates of the $\mathrm{BPH}$ induced group became hyperplastic and the lacuna became narrowed. The level of epithelial cell hyperplasia in the prostates of the finasteride-treated group decreased compared to that of the $\mathrm{BPH}$ induced group and lacuna narrowing improved to the same extent as that of the control group. As the concentration increased in the AG groups, the level of epithelial cell hyperplasia decreased. In addition, in the group treated with the high concentration of AG lacuna narrowing was abated to the same extent as that of the control group and it had a similar shape as that of the control group.

\section{Discussion}

The prostate is one of the male reproductive organs that produce part of the semen. Prostatic tissue is composed of four parts: epilepsy, line, epithelium and lumen. Histologically, $\mathrm{BPH}$ is a disease caused by the proliferation of stroma composed of the superficial follicular, connective tissue and smooth muscle. The $\mathrm{BPH}$ are caused by the compression of the prostate urethra due to the mechanical factors caused by the increase in prostate size and dynamic factors caused by the tension of the smooth muscle in the prostate $[4,22,23]$.

Table 4 Anti-oxidant indication in prostate organs

\begin{tabular}{|c|c|c|c|c|c|c|}
\hline Groups & $\begin{array}{l}\text { CAT } \\
\text { (U/mg protein) }\end{array}$ & $\begin{array}{l}\text { SOD } \\
\text { (U/mg protein) }\end{array}$ & $\begin{array}{l}\text { GST } \\
\text { (mU/mg protein) }\end{array}$ & $\begin{array}{l}\text { GR } \\
\text { (U/mg protein) }\end{array}$ & $\begin{array}{l}\text { GPx } \\
\text { (U/mg protein) }\end{array}$ & $\begin{array}{l}\text { GSH } \\
\text { ( } \mu \text { moles/mg protein) }\end{array}$ \\
\hline Control & $372.1 \pm 7.4^{\mathrm{a}}$ & $11.0 \pm 1.1^{\mathrm{a}}$ & $184.3 \pm 9.6^{a}$ & $28.8 \pm 1.1^{a}$ & $3.0 \pm 0.2^{a}$ & $72.8 \pm 3.1^{a}$ \\
\hline $\mathrm{BPH}$ & $28.0 \pm 3.7^{d}$ & $1.2 \pm 0.2^{c}$ & $7.6 \pm 3.0^{d}$ & $9.8 \pm 0.3^{c}$ & $1.5 \pm 0.1^{c}$ & $33.4 \pm 3.2^{c}$ \\
\hline Finasteride & $399.9 \pm 38.5^{b}$ & $11.1 \pm 0.2^{\mathrm{a}}$ & $141.8 \pm 11.7^{\mathrm{ab}}$ & $24.6 \pm 0.4^{\mathrm{a}}$ & $2.7 \pm 0.1^{\mathrm{a}}$ & $67.6 \pm 3.2^{\mathrm{ab}}$ \\
\hline AG 100 & $35.4 \pm 10.0^{d}$ & $6.0 \pm 0.5^{b}$ & $74.0 \pm 10.1^{c}$ & $19.9 \pm 1.8^{b}$ & $1.9 \pm 0.3^{b}$ & $34.7 \pm 2.1^{c}$ \\
\hline AG 250 & $170.5 \pm 10.9^{c}$ & $7.9 \pm 0.8^{b}$ & $71.0 \pm 23.8^{c}$ & $25.8 \pm 2.3^{\mathrm{a}}$ & $2.7 \pm 0.1^{\mathrm{a}}$ & $37.4 \pm 0.9^{c}$ \\
\hline AG 500 & $232.0 \pm 11.2^{b}$ & $11.2 \pm 0.2^{\mathrm{a}}$ & $172.2 \pm 22.1^{\mathrm{a}}$ & $26.5 \pm 0.6^{a}$ & $2.7 \pm 0.1^{\mathrm{a}}$ & $62.0 \pm 2.6^{b}$ \\
\hline
\end{tabular}

Data express the mean \pm S.E. The letters in the columns indicate statistical differences by Duncan's multiple range test $(p<0.05)$. Control: Normal rat supplied with tap water, BPH: Castrated rat supplied with tap water, AG 100: Castrated rat supplied with AG $100 \mathrm{mg} / \mathrm{kg}$ of BW daily, AG 250: Castrated rat supplied with AG $250 \mathrm{mg} / \mathrm{kg}$ of BW daily, AG 500: Castrated rat supplied with AG $500 \mathrm{mg} / \mathrm{kg}$ of BW daily. CAT: Catalase, SOD: Superoxide dismutase, GST: Glutathione S-transferase, GR: Glutathione reductase, GPx: Glutathione peroxidase, GSH: Glutathione 


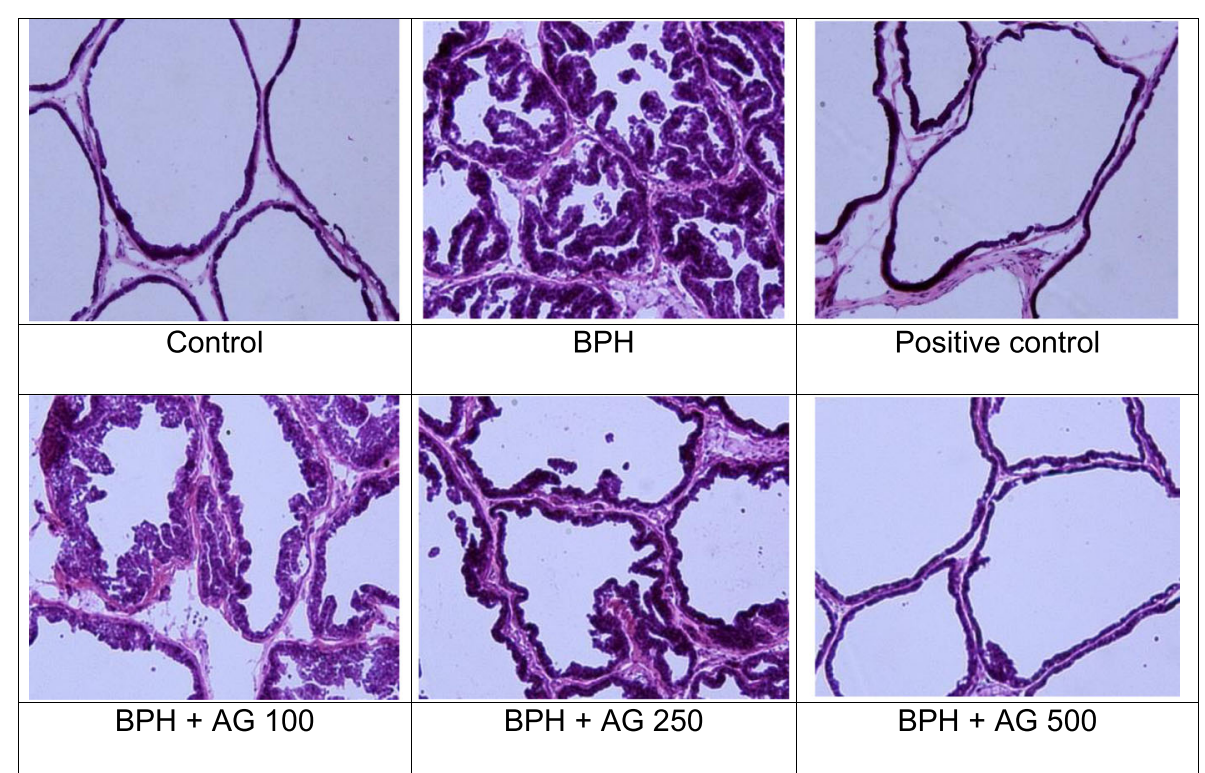

Fig. 5 Hematoxylin and eosin (H\&E) staining of prostate tissue. The prostate tissue sections were examined under an optical microscope at $\times 100$ magnification (Olympus, Tokyo, Japan). Control: corn oil, BPH: TP + corn oil, Finasteride: TP + finasteride (10 mg/kg of bw daily), BPH + AG 100, 250, $500 \mathrm{mg}$ : TP + water extract of Acorus gramineus Soland (100, 250 and $500 \mathrm{mg} / \mathrm{kg}$ of bw daily)

The representative BPH therapeutic agent, finasteride, reduces the size of the prostate gland by inhibiting the production of DHT that is involved in the proliferation of the prostate gland [24]. However, even after long term administration, the size reduction didn't exceed $30 \%$ in most cases. Moreover, even if it persisted longer, no further reduction could be expected. Therefore, the need for a safe alternative therapy has been raised [25].

Acorus gramineus is known to be effective for memory improvement, cataracts, hair and scalp health. It is perennial plant which is containing $0.5 \sim 0.9 \%$ of essential oil in roots. A. gramineus is enriched $\beta$-asarone, $\alpha$-asarone, GABA, caryophyllen, phenolic compound $[8,9]$. A recent our laboratory study confirmed the efficacy of $\mathrm{BPH}$ in vitro and will soon be published in the paper. A. gramineus is known to be toxic to mutation and carcinogenesis. Most of these are essential oils and are typically $\beta$-asarone. We used hot-water extract of A. gramineus root to remove almost toxic volatile substances. Because the toxic substance was removed by hot water extract and the efficacy of AG was confirmed in previous experiment, we studied $A$. gramineus for $\mathrm{BPH}$.

In the present study, the prostate weight and body weight were significantly increased in the BPH-induced group compared to the control group. This shows that the $\mathrm{BPH}$ is properly formed in this experimental model. As a result of observation of body weight change, statistically significant decrease was observed in $\mathrm{BPH}$-induced group, AG treated group and finasteride treated group compared to control group. In the case of AG and finasteride, the experimental group was stimulated by oral administration and weight loss was thought to be caused by such stimulation [16]. Despite weight loss, AG is thought to have antioxidant effect through various antioxidant indicator results (Table 4). As a result, the prostate weight and prostate/body weight ratio were significantly decreased in the AG-treated group, suggesting that AG is effective for enlargement of the prostate.

$\mathrm{BPH}$ is related to the male hormones, testosterone and DHT. Testosterone is converted to activated DHP by $5-\alpha$ reductase in the prostate and the activated DHT binds to androgen receptor on prostate cell to induces BPH [19]. Our results show that AG reduces the testosterone and DHT level in blood (Fig. 1). mRNA level of BPH related genes also decreased (Fig. 2) [26]. BPH is concomitant with inflammation and NF-kB inflammatory cytokines are activated. When $\mathrm{BPH}$ induces inflammation, oxygen free radicals are created and cause oxidative stress [27]. Therefore, the biomarkers, prostate weight ratio, hormonal changes, $5-\alpha$ reductase type II androgen receptor and antioxidant activation factors, were chosen to evaluate the effectiveness of AG for BPH. We confirmd the effect of AG in these markers and elucidated that AG is an effective material in $\mathrm{BPH}$ and reactive oxygen species (ROS).

\section{Conclusion}

AG is effective in inhibiting the BPH compared to the finasteride treatment group. Thus, it can be used as an field of the $\mathrm{BPH}$ treatment by supplementing the problems of the existing treatment methods. Based on the results of this study, additional clinical studies are needed for patients with $\mathrm{BPH}$. 


\section{Abbreviations}

AG: Acorus gramineus root hot water extract; ALT: Alanine aminotransferase: ANOVA: Analysis of variance; AR: Androgen receptor; AST: Aspartate aminotransferase; BPH: Benign prostatic hypertrophy; COX-2: Cyclooxygenase-2; DAD: Diode array detector; DHT: Dihydrotestosterone; FER: Food efficiency ratio; GABA: y-aminobutyric acid; GPx: Glutathione peroxidase; GR: Glutathione reductase; GSH: Glutathione; GST: Glutathione S-transferase; H\&E: Hematoxylin and eosin; HPLC: High performance liquid chromatography; IL: Interleukin; iNOS: Nitric oxide synthase; $\mathrm{Na}_{2} \mathrm{HPO}_{4}$ : Sodium phosphate dibasic anhydrous; NF-KB: Nuclear factor kappa-light-chain-enhancer of activated B cells; RTPCR: Real-time polymerase chain reaction; SDS-PAGE: Sodium dodecyl sulfate-polyacrylamide gel electrophoresis; SEM: Stander error of the mean; SOD: Superoxide dismutase; TP: Testosterone propionate

\section{Acknowledgements}

This study was performed in cooperation with the R\&D Center of BTC Co. Ltd. and Food Research Center, Jeonnam Bio-industry Foundation.

\section{Funding}

This work was supported by Convergence Technology Development Program funded by the Korea Small and Medium Business Administration in 2014-2016 (Grant No. S2175443). The funding source had no role in the study and collection, analysis and interpretation of data and in writing the manuscript.

\section{Availability of data and materials}

All data generated or analyzed during this study are included in this published article and its supplementary information files.

\section{Authors' contributions}

JMM and HMS, were major contributors in writing the manuscript, collection and editing all the data needed for this research. HJJ performed and interpreted overall physiological data regarding the in-vivo experiment. JWS produced the experimental material of Acorus gramineus and carried out analysis of marker compound, GABA, using high-performance liquid chromatography. JHW, corresponding author, supervised development of work in this study. All authors read and approved the final manuscript.

\section{Ethics approval and consent to participate}

This study was approved by the institutional Animal Care and Use Committee National University (Kwangju, Korea) (Approval number CNU IACUC-YB-2016-09).

\section{Consent for publication}

Not applicable.

\section{Competing interests}

The authors declare that they have no competing interests.

\section{Publisher's Note}

Springer Nature remains neutral with regard to jurisdictional claims in published maps and institutional affiliations.

\section{Author details}

'\#913, Technology advancement dong, Gyeonggi Technopark 705 Haean-ro, Sangnok-gu, Ansan-si, Gyeonggi-do 15588, Republic of Korea. ${ }^{2}$ Food Research Center, Jeonnam Bio-industry Foundation, 30-5

Dongsunonggongdanji-gil, Naju-si, Jeollanam-do 58275, Republic of Korea.

Received: 11 January 2017 Accepted: 21 July 2017

Published online: 22 August 2017

\section{References}

1. Heller CG, Myers GB. The male climacteric, its symptomatology, diagnosis and treatment: use of urinary gonadotropins, therapeutic test with testosterone propionate and testicular biopsies in delineating the male climacteric from psychoneurosis and psychogenic impotence. JAMA. 1944;126:472-7.

2. Han KL, Chung YK, Lee JO. A study on the relationship between stress and climacteric symptoms of midlife men. J Korean Community Nurs. 2002;13:513-22

3. Harvey J, Berny JA. Andropause in the aging male. J Nurse Pract. 2009;5:207-12.

4. Di Silverio F, Flammia GP, Sciarra A, Caponera M, Mauro M, Buscarini M, et al. Plant extracts in BPH. Minerva Urol Nefrol. 1993;45:143-9.
5. Barry M. Epidemiology and natural history of benign prostatic hyperplasia. Urol Clin North Am. 1990;17:495-507.

6. Traish AM, Hassani J, Guay AT, Zitzmann M, Hansen ML. Adverse side effects of 5a-reductase inhibitors therapy: persistent diminished libido and erectile dysfunction and depression in a subset of patients. J Sex Med. 2011:8:872-84.

7. Li S, Kim H, Lee Y, Shin H, Kang D, Lee H. Effect of Acorus gramineus on the relaxation of corpus cavernosum smooth muscle. Korean J Orien Physiol Pathol. 2011;25:863-9.

8. Della Greca M, Monaco P, Previtera L, Aliotta G, Pinto G, Pollio A. Allelochemical activity of phenylpropanes from Acorus gramineus. Phytochemistry. 1989;28:2319-21.

9. Jung YS, Park SJ, Kim JE, Yang SA, Park JH, Kim JH, et al. A comparative study of GABA, glutamate contents, acetylcholinesterase inhibition and antiradical activity of the methanolic extracts from 10 edible plants. Korean J Food Sci Technol. 2012:44:447-51.

10. Rodríguez-Páez L, Juárez-Sanchez M, Antúnez-Solís J, Baeza I, Wong C. aasarone inhibits HMG-CoA reductase, lowers serum LDL-cholesterol levels and reduces biliary CSI in hypercholesterolemic rats. Phytomedicine. 2003; 10:397-404.

11. Choi MS, Kwak HJ, Kweon K, Hwang JM, Shin JW, Sohn NW. Effects of $\beta$-asarone on pro-inflammatory cytokines and learning and memory impairment in lipopolysaccharide-treated mice. Korea J Herbology. 2013;28:119-27.

12. Thakare MM, Surana SJ. $\beta$-Asarone modulates adipokines and attenuates high fat diet-induced metabolic abnormalities in Wistar rats. Pharmacol Res. 2016:103:227-35.

13. Schmidt GH, Streloke M. Effect of Acorus calamus (L.)(Araceae) oil and its main compound $\beta$-asarone on Prostephanus Truncatus (horn)(Coleoptera: Bostrichidae). J Stored Prod Res. 1994;30:227-35.

14. Kim SD, Lee BH, Sohn DW, Cho YH, Lee SM, Kim JO, et al. The effect of herbal formulation $\mathrm{KH}-305$ mainly consisted of Rubus coreanus on benign prostatic hyperplasia-induced rat. Korean J Pharmacogn. 2008:39:80-5.

15. Jang H, Ha U, Kim SJ, Yoon BI, Han DS, Yuk SM, et al. The effects of anthocyanin extracted from black soybean on a benign prostatic hyperplasia-induced rat model. Korean J Androl. 2010;28:124-31.

16. Cho SH, Han YH, Kim YS. Effects of bee venom herbal acupuncture on experimental rat model of benign prostatic hyperplasia. Korean J Orient Int Med. 2010;31:166-76.

17. Lee SH, Ahn YM, Ahn SY, Kim YO, Lee BC. The antihyperplastic effect of oral Curcuma longa ingestion in a rat model of benign prostatic hyperplasia. Korean J Orient Int Med. 2009:30:355-64.

18. Park JJ, Lee JS, Kim YS. The effects of phellodendri cortex ex on experimental rat model of benign prostatic hyperplasia. Korean J Orient Med. 2010;16:131-41.

19. Park JS, You GD, Seo SM, Han SB, Hong JT, Han K. Inhibition effect of testosterone metabolism of some natureal products containing yacon and their ameliorative effect of benign prostatic hyperplasia symptom. Yakhak Hoeji. 2013:57:241-9.

20. Kim CW, Lee KH. Effects of Paljeong-san pharmacopuncture on experimental rat model of benign prostatic hyperplasia. J Korean Acupunct Mox Med Sci. 2014;31:95-103.

21. Oh HY, Kwon SM, Lee JR, Kim SI, Choi YD, Hong SJ. Expression of heme oxygenase-2 and smooth muscle relaxation by carbon monoxide in rat prostate: effects of age and castration. Korean J Urol. 2003:44:592-8,

22. Sun J, Xiang H, Yang LL, Chen JB. A review on steroidal 5a-reductase inhibitors for treatment of benign prostatic hyperplasia. Curr Med Chem. 2011:18:3576-89.

23. Arrighi HM, Metter EJ, Guess HA, Fozzard JL. Natural history of benign prostatic hyperplasia and risk of prostatectomy: the Baltimore longitudinal study of aging. Urol. 1991;38:4-8.

24. Tewari A, Shinahare K, Narayan P. Transition zone volume and transition zone ratio: predictor of uroflow response to finasteride therapy in benign prostatic hyperplasia patient. Urology. 1995;45:258-65.

25. Hong JE, Hong SJ. Changes in prostate volume, transitional zone volume and PSA after cessation of the finasteride. Korean J Urol. 1999:40:1519-24.

26. Carson C, Rittmaster R. The role of dihydrotestosterone in benign prostatic hyperplasia. Urology. 2003;61:2-7.

27. Bostanci Y, Kazzazi A, Momtahen S, Laze J, Djavan B. Correlation between benign prostatic hyperplasia and inflammation. Curr Opin Urol. 2013;23:5-10 